http://jmscr.igmpublication.org/home/

ISSN (e)-2347-176x ISSN (p) 2455-0450

crossref DOI: https://dx.doi.org/10.18535/jmscr/v8i6.73

Journal Of Medical Science And Clinical Research

\title{
Role of counter irritants in the etiology of Necrotizing fascitis in a survey conducted at tertiary care Government hospital
}

\author{
Authors \\ Dr R.Bhavani Rao, Dr Shalini Duvvad \\ Visakhapatnam, Andhra Pradesh, India
}

\section{Introduction}

Necrotizing Fasciitis (NF) is a relatively common, rapidly progressing infection affecting the superficial fascia and subcutaneous tissue, accompanied by severe systemic toxicity and multiorgan failure. The rate of spread is directly proportional to the thickness of the subcutaneous tissue. Necrotizing fasciitis moves along the fascial plane. ${ }^{[1,2]}$.

Early diagnosis of case with necrotizing fasciitis is always a challenge for surgeons because of the vague presentation, lack of clear boundaries and palpable limits between viable, nonviable and infected tissue. There is a layer of necrotic tissue which is not walled off by an inflammatory reaction. Overlying skin has a relatively normal appearance in early stages of infection and visible degree of involvement is substantially less than actual pathology. Management of this disease still remains suboptimal with mortality rates of approximately $30 \%$.

The term necrotising fasciitis was first used by Wilson $^{[3]}$ in 1952 to describe the most consistent feature of the infection, necrosis of the fascia and subcutaneous tissue with relative sparing of the underlying muscle. It can progress rapidly to systemic toxicity and even death if not promptly diagnosed and treated. Once suspected, management should consist of immediate resuscitation, early surgical debridement, and administration of broad spectrum intravenous antibiotics.

It has been a practice of ignorant people mostly belonging to lower and middle socioeconomic groups to apply Ayurvedic balms for body aches and minor cuts. A Counterirritant is an agent that causes irritation or a mild inflammati on of the skin to relieve symptoms of a deep seated inflammatory process. The balms contain counterirritants like Gaultheria, Eucalyptus Globulus, camphor, menthol, cajuput oil, mint oil and clove oiletc. The authors believe that some of the contents of these balms may be the etiological factor for Necrotizing fasciitis. A retrospective study was conducted in tertiary Government teaching hospital, South India to find out any association between applications of these balms in the causation of NF.

A retrospective cohort study, also called a historic cohort study, is a longitudinal cohort study that studies a cohort of individuals that share a common exposure factor to determine its influence on the development of a disease, and are compared to another group of equivalent individuals that were not exposed to that factor. 


\section{Clinical features of necrotizing fasciitis. ${ }^{[4]}$}

Erythema with ill-defined margins of the skin involved, Tense edema with grayish or brown discharge, Lack of lymphangitis or lymphadenopathy, Vesicles or bullae, hemorrhagic bullae, necrosis and crepitus. severe pain, which is out of proportion to physical findings and that extends past the margin of apparent infection. Decreased pain or anaesthesia at apparent site of infection. Severe disease may present with fever with toxicity, altered mental state and multiorgan failure and death.

\section{Objective of the Study}

The main objective of this study is to identify association between the application of counter irritants and subsequent precipitation of symptoms of Necrotizing Fasciitis and to identify the common ingredients of counter-irritants that are causatives of the disease.

\section{Methods}

\section{Study Design}

Conducted a retrospective cohort study on patients in a tertiary care hospital affected by Necrotizing Fasciitis with / without a history of use of counter irritants. In the present study a format of questionnaires is prepared to obtain following data from the patients diagnosed with Necrotizing fasciitis. The data elements are Name, Gender, Phone number, history of application of any counterirritants like Brand A (Amrutanjan), Brand B (Zandu balm), Brand C (Tiger balm), Brand D (Moov), Brand O (Others-Specify). Brand names and their photographs are printed on the questionnaire for easy identification by the patients.

The brand A (Amrutanjan) Pain balmKarpoor powder, Ajawankaphool, Pudinakaphool, Turpentine katel, Pudinakatel, Gandhapuratel, Nilgirikatel, Chahakatel, Dalchinikatel, Ganjinika tel.

The brand B (Zandu Balm) contains: Mentha Sp. Satva: 14.0\%, Gaultheria Fragrantissima: OL. $12.0 \%$, Eucalyptus Globulus: OL. 0.80\%.
The brand $\mathrm{C}$ (Tiger Balm) contains: Camphor $(11 \%)$ and Menthol (10\%)

The brand D (Moov Cream) is made from wintergreen oil, pudinakephool (mint leaves), tarpinkatel (turpentine oil) and eucalyptus oil (nilgiritel) which are all beneficial in providing instant pain relieving action.

The associated co morbid conditions like Diabetes Mellitus, Obesity, Malnutrition, Peripheral vascular diseases, Others- specify were also noted. Study Population: 60 patients affected by Necrotizing Fasciitis.

Study Place One Government teaching tertiary care hospital, Government General Hospital Guntur, India.

Study Period: April 2016- September 2016.

Selection Criteria: Both the Inclusion and the Exclusion criteria.

Inclusion Criteria: Patients who are affected with Necrotising fasciitis and are willing to participate in the survey.

Exclusion Criteria: 1.Patients who are not willing to participate in the survey. 2. Patients who were suffering from chronic ulcers with peripheral vascular disease, atherosclerosis, venous ulcers and Thrombo-angitis obliterans were excluded from the study.

Ethical Considerations: Institutional ethics committee approval was obtained before conducting the study. Permissions were taken from the concerned hospital.

Data Analysis: Data was analysed by standard statistical methods to obtain $\mathrm{p}$ value

\section{Results}

The patients surveyed were 60 , out of which 28 patients confessed to application of a balm and 32 people denied of their usage. The $\mathrm{P}$ value of counter irritants is $>0.05$. Hence, it is statistically insignificant by standard proportion test. The $\mathrm{P}$ value of Brand B is $<0.05$. Hence it is statistically significant by i square test. 
Table 1: Distribution of cases based on usage of counter-irritants

\begin{tabular}{|l|c|}
\hline $\begin{array}{l}\text { History application of } \\
\text { counterirritants-brands }\end{array}$ & $\begin{array}{c}\text { Number of } \\
\text { Patients }\end{array}$ \\
\hline Brand A (amrutanjan) & 0 \\
\hline B & 18 \\
\hline C & 5 \\
\hline D & 5 \\
\hline TOTAL & 28 \\
\hline
\end{tabular}

$84 \%$ of males and $16 \%$ females are affected.

The most common affected age group is 61 to 70years $(35 \%)$

Table 2: Age distribution of affected individuals with necrotizing fasciitis

\begin{tabular}{|l|c|}
\hline AGE & INCIDENCE OF NF \\
\hline $\mathbf{1 1 - 2 0}$ & $1 \%$ \\
\hline $\mathbf{2 1 - 3 0}$ & $5 \%$ \\
\hline $\mathbf{3 1 - 4 0}$ & $8 \%$ \\
\hline $\mathbf{4 1 - 5 0}$ & $10 \%$ \\
\hline $\mathbf{5 1 - 6 0}$ & $23 \%$ \\
\hline $\mathbf{6 1 - 7 0}$ & $35 \%$ \\
\hline $\mathbf{7 1 - 8 0}$ & $11 \%$ \\
$\mathbf{8 1 - 9 0}$ & $3 \%$ \\
$\mathbf{9 1 - 1 0 0}$ & $1 \%$ \\
\hline
\end{tabular}

The number of patients with Diabetes Mellitus are $18 \%$, Obesity 3\%, Malnutrition 1\%, Peripheral Vascular Diseases $11 \%$, and others are $10 \%$.

Retrospective analysis of the survey revealed mere application of counter irritant may not be a etiological factor in the causation of NF as evidenced by the $\mathrm{P}$ value of counter irritants is $>0.05$. It is statistically insignificant by standard proportion test. On the other hand, the $\mathrm{P}$ value of brand $\mathrm{B}$ is $<0.05$ and is statistically significant by i square test.

Cases are admitted and treated in surgical department of Government general hospital, Guntur from February 2016 to August 2016.

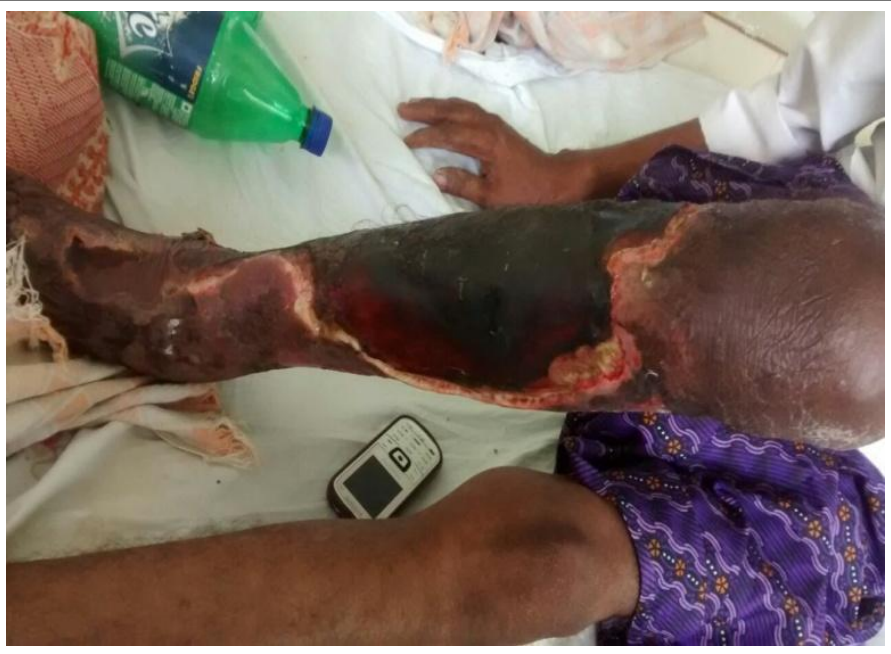

Figure 1: Necrotizing fasciitis of lower limb

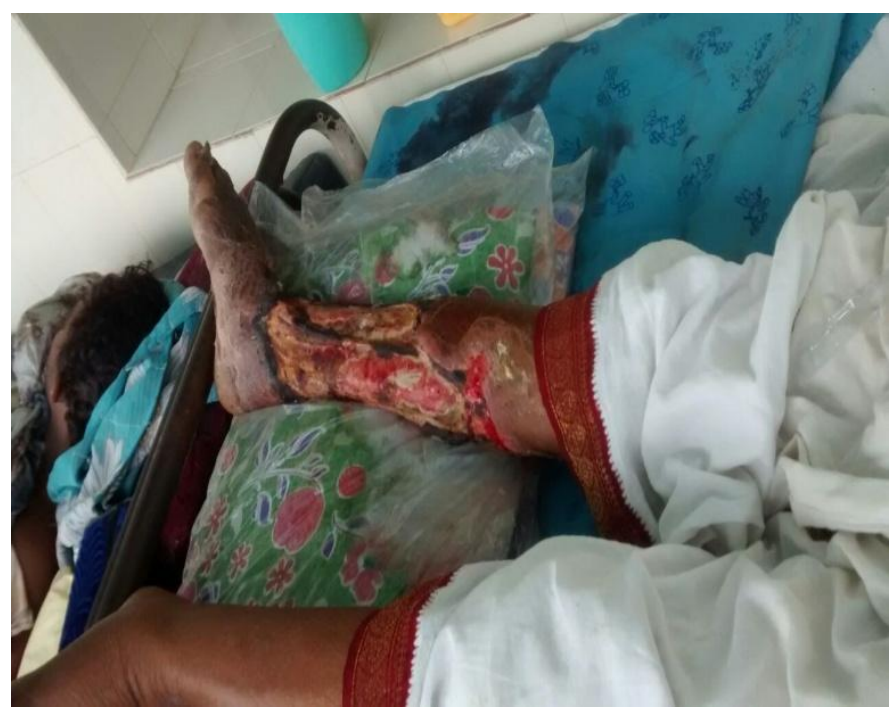

Figure 2: Necrotizing fasciitis of lower limb

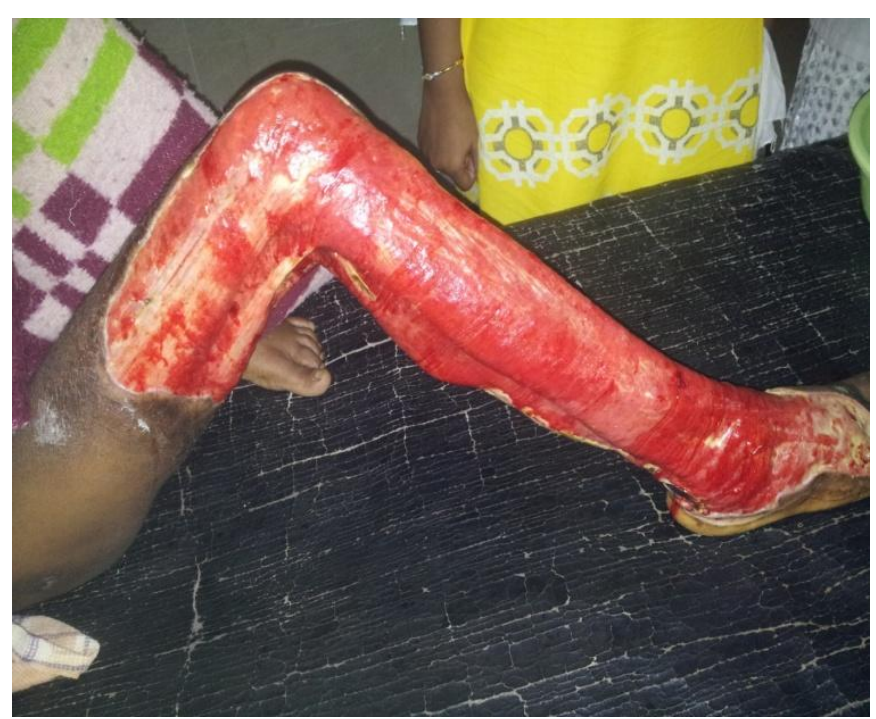

Figure 3: Post debridement picture of necrotizing fasciitis lower limb. 


\section{Discussion}

About $20 \%$ beds of septic ward of a government general hospital are occupied by the cases of Necrotizing Fasciitis. Necrotizing Fasciitis is a spreading bacterial infection at times with blister formation. It is not an uncommon disease that results in gross morbidity and mortality. Patients with Necrotizing Fasciitis present with symptoms of sepsis, systemic toxicity or evidence of skin inflammation with pain that is disproportional to the degree of inflammation. Necrotizing Fasciitis is precipitated by application of counterirritants like menthol, camphor, thymol etc. to relive muscle pains and body aches. Counterirritants are also applied on the skin for curing minor cuts, ulcers and skin diseases. Necrotizing Fasciitis manifests itself by blister formation and peeling off of skin revealing yellowish white liquefied subcutaneous tissues and later turning it into jelly of thick pus. Necrotizing Fasciitis is common in lower limbs and perineum. In our opinion the etiological agents for the causation of this life threatening disease which causes prolonged morbidity are not complete. The pathological events subsequent to application of counterirritants can only be an educated guess due to lack of adequate studies. If the hypothesis of counter irritant induced Necrotizing Fasciitis is proved, it stimulates further research in the area and helps in undertaking preventive measures.

The frequency of necrotizing fasciitis has been on the rise because of an increase in immunocompromised patients with diabetes mellitus, cancer, alcoholism, vascular insufficiencies, organ transplants, HIV infection, or neutropenia.

Since 1883, more than 500 cases of necrotizing fasciitis have been reported in the literature. There may be an increased incidence in African and Asian countries; However, because of the lack of recorded cases, the true incidence is not known. The mean age of a patient with necrotizing fasciitis is $38-44$ years. The male to female ratio is 2:1.These infections can be difficult to recognize in their early stages, but they rapidly progress.
They require aggressive treatment to combat the associated high morbidity and mortality.

Literature search using Medical Subject Headings (MESH) terms "necrotizing fasciitis and counter irritant" returned only a single scholarly article showing Counterirritant as an etiological agent in NF. ${ }^{[7]}$. In the absence of evidence the pathology of counter irritant induced $\mathrm{NF}$ can only be an educated guess.

PUBMED and MEDLINE search did not reveal any articles showing counter irritants as an etiological agent.

Agents commonly known as poisons cause severe damage at the cellular level by altering membrane permeability, osmotic homeostasis, or the integrity of an enzyme or cofactor, and exposure to these poisons can culminate in the death of the whole organism. Even therapeutic drugs can cause cell or tissue injury in a susceptible patient or if used excessively or inappropriately. Toxin-induced vascular occlusion, a mechanism similar to that occurs in classical NF may also be the underlying cause $^{[9]}$. We believe one of the above mechanisms alone or in combination is the underlying pathological pathway.

Menthol (pudinakephool, mint leaves) are ingredients in brand B,C and D. Eucalyptus (nilgiritel) and Gaultheria (wintergreen oil) are ingredients in brand $\mathrm{B}$ and $\mathrm{D}$. The brand $\mathrm{D}$ warns against application of its cream on skin cut, obviously aware of its ill effects.

The brand $\mathrm{A}$ is intended for headache and none of the respondents applied for cuts or body aches.

\section{Conclusion}

The role of counter irritants in the etiology of Necrotizing fascitis has been investigated in a survey conducted at tertiary care hospital, Guntur. Contrary to expectations, brand A was not applied for small cuts and body aches and its role in NF is not known. Brand B was mostly used. Menthol, Eucalyptus and Gaultheria were the active ingredients that are present in all the brands and can be one of the etiological agents for NF. 
They should be investigated further individually as well as in combination. . The pathological events subsequent to application of counterirritants can only be an educated guess due to lack of adequate studies. If the hypothesis of counter irritant induced Necrotizing Fasciitis is proved, it stimulates further research in the area and helps in undertaking preventive measures.

\section{References}

1. Misiakos EP, Bagias G, Patapis P, Sotiropoulos D, Kanavidis P, Machairas A. Current concepts in the management of necrotizing fasciitis. Front Surg. 2014. 1:36. [Medline].

2. Hakkarainen TW, Kopari NM, Pham TN, Evans HL. Necrotizing soft tissue infections: review and current concepts in treatment, systems of care, and outcomes. CurrProbl Surg. 2014 Aug. 51 (8):34462.[Medline].

3. Wilson B. Necrotising fasciitis. Am Surg 1952;18:416-31.

4. Abhishek Vijayakumar, Rajeev Pullagura, and Durganna Thimmappa, "Necrotizing Fasciitis: Diagnostic Challenges and Current Practices," ISRN Infectious Diseases, vol. 2014, Article ID 208072, 8 pages, 2014.

5. Elliot D, Kufera JA, Myers RA. The microbiology of necrotizing soft tissue infections.Am J Surg2000;179(5):361-6.

6. Dufel S, Martino M. Simple cellulitis or a more serious infection? J Fam Pract 2006; 55(5):396-400.

7. Reddi BR, Korukonda B, Palanki G. Necrotizingfasciitis: Role of counter irritants in the etiology. J Dr NTR Univ Health Sci2013;2:25-8.
8. Kumar, Abbas, Fausto, Mitchell. Overview of cellular responseto stress and noxious stimuli. Robbins's Basic pathology. vol. 8.Philadelphia: Saundres Elselvier; 2011.p. 7

9. Schwartz B, Facklam RR, Breiman RF. Changing epidemiology ofgroup A streptococcal infection in the USA. Lancet 1990;336:1167-71. 